\title{
Evaluation of Agricultural Water Resources Carrying Capacity in Taihang Mountain Area
}

\author{
Hong-Yao Liu ${ }^{1}$, Li-Hua Wen²,3* \\ ${ }^{1}$ Handan Institute of Agricultural Science, Handan 056001, China; E-mail: hykct@163.com \\ ${ }^{2}$ Department of Geography, Handan University, Handan 056001, China; E-mail: lwqijia@126.com \\ ${ }^{3}$ College of Resources and Environment, Huazhong Agricultural University, Wuhan 430070, China; E-mail: lwqijia@126.com
}

\begin{abstract}
Based on the relevant data of nature, society, economics and water resources of eight sub-areas of Taihang Mountain area from 2016, this paper selected six main evaluation factors including use efficiency of water resources, water deficient ratio, irrigation ration of arable land, precipitation amount of precipitation, per capita water resources and ecological water use ratio, and quantitatively researched water resources carrying capacity of eight sub-areas by using the fuzzy comprehensive evaluation method. The evaluated results show that the comprehensive grade of the study area was higher than 0.614 , and the current water exploitation and utilization have reached a considerable scale, but still has certain potentiality. Overall, water resources supply and demand are able to partly satisfy the regional development in the the study area. For the eight sub-areas, the water resources carrying capacity status is very different. Handan, Xingtai and Shijiazhuang have a weak water resources carrying capacity, while water resources carrying capacity of other sub-areas is relatively strong. Finally, according to different regions of the water resources carrying condition, this paper puts forward the corresponding measures in Taihang Mountain Area.
\end{abstract}

\section{Introduction}

With a shortage of water resources in China, coupled with frequently occurring drought and flood disaster, the fact of distribution of area and water resources, mismatch between soil and water resources layout, and increasingly sharp contradiction between supply and demand of water, which results in water resource shortage and the deterioration of water environment has become important factors of restricting China's social and economic sustainable development[1,2]. Along with the sustainable development theory, people in the society have a profound understanding on the relationship between sustainable development and water environment and then put forward the concept of water resources carrying capacity, which is threshold value of water resources supporting social, economic, ecological environment and sustainable development $[3,4]$. Yafeng Shi made a scientific definition of water resources carrying capacity, which meant that in a certain social and science and technology development stage, without destroying the social and ecological system, water resources in a certain area are the maximum load of agriculture, industry, city size and population levels, and also are a comprehensive target that changed with the level of social economy and science and technology development $[5,6]$. On the contrary, domestic correlational studies start late, and research field is mainly concentrated in two aspects of city water resources carrying capacity and river basin water resources carrying capacity, which mainly focus on case studies, but be short of entire or system research in the northern water shortage area, as well as comparative study among the provincial inter-domain [7,8]. Water resources carrying capacity evaluation methods are often with the aid of statistical model, such as the tendency method, the system dynamics method, principal component analysis entropy weight method, and neural network.

\section{Methodology}

\subsection{Data}

The basic data used for this study included the water resources data, population data and social economic data. Six main assessment factors including use efficiency of water resources, water deficient ratio, irrigation ration of arable land, precipitation amount of precipitation, per capita water resources and ecological water use ratio are selected.

\subsection{Fuzzy comprehensive evaluation model}

\subsubsection{Fuzzy set theory}

Fuzzy set theory widely used as a modeling approach for complex systems that are difficult to define exactly in 
crisp numbers. Fuzzy comprehensive assessment model can be described as follows:

Firstly, given set of assessment factors $U=\left\{u_{1}, u_{2}, \ldots, u_{m}\right\}$ and the fuzzy assessment set $Z=\left\{z_{1}, z_{2}, \ldots, z_{n}\right\}$

we perform a single factor evaluation and determine the factors $u_{i}(i=1,2, \ldots m)$ for the membership degree $\left({ }^{r_{i j}}\right)$ of assessment grade $z_{j}(j=1,2, \ldots n)$

$\mathrm{R}$ is a fuzzy relationship from $\mathrm{U}$ to $\mathrm{Z}$.

Then on the basis of expert weight value for each assessment factor, the comprehensive evaluation results can be obtained by applying the fuzzy transformation as follows:

$$
\left(\begin{array}{cccc}
r_{11} & r_{12} & \cdots & r_{1 n} \\
r_{21} & r_{22} & \cdots & r_{2 n} \\
\vdots & \vdots & \vdots & \vdots \\
r_{m 1} & r_{m 2} & \cdots & r_{m n}
\end{array}\right)=\left(b_{1}, b_{2}, \cdots, b_{n}\right)
$$

Finally, according to the assessment set value ${ }^{a_{j}}$ and the membership degree $\left({ }^{b_{j}}\right)$ in the $B$ matrix, this formula can also be expressed as

$$
a=\frac{\sum_{j=1}^{n} b_{j} \alpha_{j}}{\sum_{j=1}^{m} b_{j}}
$$

Where, ${ }^{\alpha_{j}}$ is the corresponding value of the ${ }^{j}$ grade after the assessment grade of 1 points system to quantify. ${ }^{a}$ is the comprehensive score of water resources carrying capacity of assessment result matrix $B$,the greater the ${ }^{a}$ which can also be represented the greater the potential of water resources in the study area.

\subsubsection{Selection, grading and scoring of assessment factors}

In order to better reflect the situation of water resources carrying capacity at all grades,we have to score 1 to 0 of the evaluation levels, specific to $\alpha_{1}=0.05, \alpha_{2}=0.5, \alpha_{3}=0.95$, in this way, so as to better reflect the influence degree of each grade on water resources carrying capacity, the higher the value, the greater the potential for water resources development capacity.

\subsubsection{Formula for calculating the membership degree of assessment factors}

Referring to the related articles, according to the actual value of the various assessment factors and the classification index of each factor, the method derives the value of membership function $r_{i j}$ of the evaluation matrix R.The fuzzy treatment to eliminate numerical difference between different grades and grade difference jump phenomenon, make a smooth transition between different levels. For the assessment of factors $u_{1}, u_{2}, u_{3}$, each comment class membership function formula:

$$
r_{i 1}=\left\{\begin{array}{cc}
0.5\left(1+\frac{u_{i}-k_{1}}{u_{i}-k_{2}}\right) & u_{i}>k_{1} \\
0.5\left(1-\frac{k_{1}-u_{i}}{k_{1}-k_{2}}\right) & k_{2}<u_{i} \leq k_{1} \\
0 & u_{i} \leq k_{2}
\end{array}\right\}
$$

For the assessment of factors $u_{4}, u_{5}, u_{6}$, each comment class membership function formula:

$$
r_{i 1}=\left\{\begin{array}{cc}
0.5\left(1+\frac{k_{1}-u_{i}}{k_{2}-u_{i}}\right) & u_{i}<k_{1} \\
0.5\left(1-\frac{u_{i}-k_{1}}{k_{2}-k_{1}}\right) & k_{1} \leq u_{i}<k_{2} \\
0 & u_{i} \geq k_{2}
\end{array}\right.
$$

Where, ${ }^{k_{1}}$ is the critical value for the grades of ${ }^{z_{1}}$ and $z_{2}$, and $k_{3}$ is the critical value for the grades of $z_{2}$ and $\mathrm{z} 3$, and $k_{2}$ is the median value for the grades of $z_{2}$ which can be defined as $k_{2}=\frac{k_{1}+k_{3}}{2}$.

\section{Comprehensive evaluation of water resources carrying capacity}

\subsection{Evaluation process}

The values of the comprehensive evaluation matrix $\mathrm{R}$ are obtained.Use efficiency of water resources and water 
deficient ratio of the nine factors have great impact on water resources carrying capacity, and give the weight of 0.25 , the weight matrix is $A=\{0.25,0.25,0.1,0.1,0.2,0.1\}$ Based on the fuzzy comprehensive evaluation model, the final result matrix of water resources carrying capacity $B=\left(b_{1}, b_{2}, b_{3}\right)$ can be obtained by using the general matrix calculation rule $B=A \bullet R$. Then according to the formula $a=\frac{\sum_{j=1}^{n} b_{j} \alpha_{j}}{\sum_{j=1}^{m} b_{j}}=\left(\alpha_{1}, \alpha_{2}, \alpha_{3}\right)$ - $\left(b_{1}, b_{2}, b_{3}\right)^{T}$, the comprehensive scores of water resources carrying capacity are obtained in different regions.

\subsection{Evaluation results and analysis}

Table 1 Integrated assessment values of the carrying capacity of agricultural water resources in different regions

\begin{tabular}{ccccc}
\hline Different regions & $z_{1}$ & $z_{2}$ & $z_{3}$ & Score \\
\hline Xingtai city & 0.395 & 0.411 & 0.194 & 0.399 \\
Shijiazhuang city & 0.659 & 0.242 & 0.099 & 0.248 \\
Handan city & 0.676 & 0.235 & 0.089 & 0.236 \\
Baoding city & 0.234 & 0.366 & 0.400 & 0.574 \\
Jinzhong city & 0.035 & 0.350 & 0.615 & 0.749 \\
Changzhi city & 0.201 & 0.277 & 0.522 & 0.645 \\
Anyang city & 0.271 & 0.273 & 0.456 & 0.583 \\
Xinxiang city & 0.241 & 0.273 & 0.486 & 0.610 \\
The study area & 0.231 & 0.285 & 0.484 & 0.614 \\
\hline
\end{tabular}

(1) The supply and demand situation of water resources in Taihang Mountain area is relative balance, but with the development of economy and society, the shortage of water resources will become increasingly prominent. The resources shortage situation in the cities of Handan, Shijiazhuang and Xingtai is quite grim. In the future, we must in the full use of water resources produced by, the full implementation of the high-tech and modern water-saving technologies, strengthen public awareness of water saving, water resources protection and management up to a strategic height;increase inter water transfer project implementation efforts, prevention and treatment for a long time sustained exploitation of groundwater to the north of ecological agriculture caused negative impact.

(2) The analysis of Z1, Z2 and Z3 membership degree of each index in Henan province, can be found the impact of water resources bearing force change is a major factor in the increasing pressure of population and agriculture irrigation water in recent years, the contradiction between population and environment is still outstanding. We should be continue to adhere to the family planning to promote balanced development of long-term population;reasonable adjustment of economic structure and industrial structure,develop the low consumption of aquaculture, improve the agricultural, industrial and domestic water system, so as to improve the bearing capacity of water resources.

(3) Changzhi city and Jinzhong city belong to a resource type of severe water shortage area in Shanxi province, improving climate condition and ecological environment quality improvement are the fundamental of sustainable utilization of water resources of the region. We should further maintain soil water conservation, improve the regional vegetation coverage, to establish alternative agricultural production system to adapt to semi arid climate change and to response to the agriculture water resource shortage. Establish water-saving agriculture production mode to improve the utilization efficiency of water resources, utilization benefit as the center and regional economic development.

\section{Conclusion}

The results of analyzing water resources carrying capacity of eight sub-areas in Taihang Mountain area by using fuzzy evaluation model show that under the overall situation water resources development and utilization have a certain scale, though there are still some potentially, but the situation of water resources carrying capacity in eight sub-areas is very different. The water resources development of Hebei is close to saturation value and the carrying capacity is quite fragile, further the potential of further development and utilization is quite small. The development of water resources in other cities is still a certain potentially. Through analyzing the relationship matrix of each evaluation index and evaluation grade, the following countermeasures are put forward to the management of water resources in eight sub-areas in Taihang Mountain area.

\section{Acknowledgments}

Financial support for this work was provided by Handan Science and Technology Planning Project (1621203035-1), University-level Project of Handan University (2018225), Scientific and Technological Research Projects of Universities in Hebei Province (ZD2016210)

\section{References}

1. Liu, J.J.; Dong, S.C.; Li, Z.H. Comprehensive evaluation of China's water resources carrying capacity.J. Nat. Resour. 2011, 26, 258-269.

2. Wang, C.; Yang, G.; He, X.L.; Chen, S.; Li, X.L. Research on water resources carrying capacity Based on system dynamics. China Rural Water Hydropower 2016, 9, 212-215.

3. Mo Li,Hao Sun,Vijay P. Singh.Agricultural water resources management using maximum entropy and entropy weight-Based TOPSIS methods.entropy. 2019, 21(4), 364.

4. Singh, V.P. Entropy-based parameter estimation in hydrology; Kluwer Academic Publishers: Boston, MA, USA;London, UK, 1998.

5. Falkenmark M, Lundqvist J. Towards water security: political determination and human adaptation crucial [J].Natural resources forum, 1998(21)3:37-51. 
6. Fan, Y.Y.; Liu, Y.; Guo, H.C.; Wang, S.T. The effects of water resources policies on water resources carrying capacity in Beijing city. Resour. Sci. 2005, 27, 113-119.

7. Dai, Z.Y.; Li, Y.P. A multistage irrigation water allocation model for agricultural land-use planning under uncertainty. Agric. Water Manag. 2013, 129, 69-79.

8. Shi, Y.F.; Qu, Y.G. Water resources carrying capacity and rational development and utilization of Urumqi river;science: Beijing, China, 1992 